\title{
Chronic sustained hypoxia-induced redox remodeling causes contractile dysfunction in mouse sternohyoid muscle
}

\author{
Philip Lewis ${ }^{1}$, David Sheehan ${ }^{2}$, Renata Soares ${ }^{3}$, Ana Varela Coelho ${ }^{3}$ and \\ Ken D. O'Halloran ${ }^{1 *}$ \\ ${ }^{1}$ Department of Physiology, School of Medicine, University College Cork, Cork, Ireland, ${ }^{2}$ School of Biochemistry and Cell \\ Biology, University College Cork, Cork, Ireland, ${ }^{3}$ Instituto de Tecnologia Química e Biológica António Xavier, New University of \\ Lisbon, Lisbon, Portugal
}

\section{OPEN ACCESS}

Edited by:

Brian McDonagh,

University of Liverpool, UK

Reviewed by:

Leonardo F. Ferreira, University of Florida, USA

Esther Barreiro,

Institut Hospital del Mar $d^{\prime} I$ Investigacions Mèdiques, Spain

*Correspondence: Ken D. O'Halloran, Department of Physiology, School of Medicine, University College Cork, 3-079, Western Gateway Building,

Western Road, Cork, Ireland k.ohalloran@ucc.ie

Specialty section This article was submitted to Striated Muscle Physiology, a section of the journal

Frontiers in Physiology

Received: 16 January 2015 Accepted: 02 April 2015 Published: 20 April 2015

Citation:

Lewis $P$, Sheehan $D$, Soares $R$, Varela Coelho A and O'Halloran KD (2015) Chronic sustained hypoxia-induced redox remodeling causes contractile dysfunction in mouse sternohyoid muscle. Front. Physiol. 6:122. doi: 10.3389/fphys.2015.00122
Chronic sustained hypoxia $(\mathrm{CH})$ induces structural and functional adaptations in respiratory muscles of animal models, however the underlying molecular mechanisms are unclear. This study explores the putative role of $\mathrm{CH}$-induced redox remodeling in a translational mouse model, with a focus on the sternohyoid-a representative upper airway dilator muscle involved in the control of pharyngeal airway caliber. We hypothesized that exposure to $\mathrm{CH}$ induces redox disturbance in mouse sternohyoid muscle in a time-dependent manner affecting metabolic capacity and contractile performance. C57Bl6/J mice were exposed to normoxia or normobaric $\mathrm{CH}\left(\mathrm{FiO}_{2}=0.1\right)$ for 1 , 3, or 6 weeks. A second cohort of animals was exposed to $\mathrm{CH}$ for 6 weeks with and without antioxidant supplementation (tempol or $\mathrm{N}$-acetyl cysteine in the drinking water). Following $\mathrm{CH}$ exposure, we performed 2D redox proteomics with mass spectrometry, metabolic enzyme activity assays, and cell-signaling assays. Additionally, we assessed isotonic contractile and endurance properties ex vivo. Temporal changes in protein oxidation and glycolytic enzyme activities were observed. Redox modulation of sternohyoid muscle proteins key to contraction, metabolism and cellular homeostasis was identified. There was no change in redox-sensitive proteasome activity or HIF-1 $\alpha$ content, but $\mathrm{CH}$ decreased phospho-JNK content independent of antioxidant supplementation. $\mathrm{CH}$ was detrimental to sternohyoid force- and power-generating capacity and this was prevented by chronic antioxidant supplementation. We conclude that $\mathrm{CH}$ causes upper airway dilator muscle dysfunction due to redox modulation of proteins key to function and homeostasis. Such changes could serve to further disrupt respiratory homeostasis in diseases characterized by $\mathrm{CH}$ such as chronic obstructive pulmonary disease. Antioxidants may have potential use as an adjunctive therapy in hypoxic respiratory disease.

Keywords: hypoxia, oxidative stress, antioxidants, respiratory muscle, COPD 


\section{Introduction}

The striated muscles of breathing are the final common effectors of the respiratory control system, critical in the maintenance of respiratory homeostasis. Pharyngeal dilator muscles are an important subset of the respiratory muscles serving to control the patency of the upper airway. Pharyngeal dilator muscle damage or dysfunction increases the risk of obstructive airway events. Upper airway muscle dysfunction is implicated in human obstructive sleep apnea (OSA), a common respiratory disorder characterized by repeated occlusions of the pharyngeal airway during sleep. Of note, OSA is prevalent in patients with chronic obstructive pulmonary disease (COPD), presenting as the "overlap syndrome" (Owens et al., 2008; McNicholas, 2009; Owens and Malhotra, 2010), but the reasons for the emergence of this co-morbidity are unclear.

Chronic sustained hypoxia $(\mathrm{CH})$ is a dominant feature of respiratory diseases including $\mathrm{COPD}$, but the putative role of $\mathrm{CH}$ in respiratory muscle remodeling and dysfunction is generally under-explored. Little is known about the effects of $\mathrm{CH}$ exposure on the respiratory muscles and there exists a general paucity of information concerning the pharyngeal dilator muscles despite the potential clinical relevance. Respiratory and limb muscle remodeling are features of COPD (Orozco-Levi, 2003; Doucet et al., 2004, 2010; Levine et al., 2013) and interestingly, exposure to $\mathrm{CH}$ elicits differential structural and functional adaptations in respiratory and limb muscles (El-Khoury et al., 2003, 2012; Faucher et al., 2005; McMorrow et al., 2011; Gamboa and Andrade, 2012; Carberry et al., 2014). We speculate that hypoxic remodeling of respiratory muscle has relevance to respiratory muscle plasticity in respiratory disease. Hypoxia-related remodeling of upper airway muscles may underpin poor upper airway control in COPD.

Pharyngeal dilator muscles are phasically active during inspiration and muscle activity is increased during hypoxic exposure (O'Halloran et al., 2002; Edge et al., 2014). Contractile activity increases reactive oxygen species (ROS) production which are pivotal for muscle adaptation to high altitude and respiratory diseases characterized by hypoxia (Zuo and Clanton, 2005; Marin-Corral et al., 2009; Murray, 2009; Chaudhary et al., 2012; El-Khoury et al., 2012; Levine et al., 2013; Puig-Vilanova et al., 2015). Thus, CH likely challenges respiratory muscles, including the pharyngeal dilator muscles, with enhanced ROS on two fronts-increased contractile activity during reflex hyperventilation and hypoxia per se. We postulated a role for ROS in eliciting $\mathrm{CH}$-induced redox remodeling of key muscle proteins with resultant functional changes in the sternohyoid muscle-a representative pharyngeal dilator muscle. The supra- and infra-hyoid muscles of the upper airway control the position of the hyoid bone, displacing it anteriorly during inspiration to enlarge the caliber of the pharynx. Sternohyoid muscle length correlates to airway volume (Van Lunteren et al., 1987) and the muscle is recruited during increased respiratory drive (O'Halloran et al., 2002) and obstructive airway events (Edge et al., 2012). Sternohyoid muscle damage is reported in the English bulldog, an animal model of OSA (Petrof et al., 1994). We have extensively characterized sternohyoid muscle physiology (O'Halloran, 2006;
Skelly et al., 2010; Shortt and O'Halloran, 2014; McDonald et al., 2015), including several studies in animal models of chronic hypoxia (Bradford et al., 2005; McMorrow et al., 2011; Skelly et al., 2011, 2012a,b, 2013; O'Connell et al., 2013; Carberry et al., 2014; McDonald et al., 2014). The sternohyoid muscle is suited to ex vivo study of contractile function due to ease of access, longitudinal arrangement of its fibers and the opportunity, employed in the present study, to keep bony origin and insertions intact in isolated preparations.

Given that ventilation, muscle contractile behavior, and the level of hypoxia experienced by the respiratory muscles, are likely temporally modified during the process of acclimatization to $\mathrm{CH}$, we characterized protein carbonyl and free thiol content (the most common and most specific form of protein oxidation respectively (Dalle-Donne et al., 2006; El-Shafey et al., 2011) in the sternohyoid after 1,3 , or 6 weeks of $\mathrm{CH}$ exposure. In addition, we sought to identify redox-modified proteins in the sternohyoid muscle after 6 weeks of $\mathrm{CH}$ using $2 \mathrm{D}$ redox proteomics combined with mass spectrometry (Cole et al., 2014; Hu et al., 2014; Rainville et al., 2014) having reasoned that this information will aid the determination of how and where ROS exert their effects in muscle cells following $\mathrm{CH}$ exposure. We postulated that chymotrypsin-like activity of the $20 \mathrm{~S}$ proteasome is increased in the sternohyoid after 6 weeks of $\mathrm{CH}$ given that proteasomal activity is highly sensitive to ROS (McClung et al., 2008; Aiken et al., 2011). Hypoxia through the hypoxia-inducible factor (HIF)- $1 \alpha$ transcription factor promotes a more glycolytic phenotype in tissues to reduce the reliance on oxygen in ATP production (Howald et al., 1990; Murray, 2009; Wheaton and Chandel, 2011). HIF expression correlates with muscle fiber type and activity and is also modulated by ROS. Therefore, we reasoned that glyceraldehyde-3-phosphate dehydrogenase (GAPDH) and lactate dehydrogenase (LDH) activities would be temporally modified in the sternohyoid in response to $\mathrm{CH}$ exposure. We also assessed HIF- $1 \alpha$ content, phospho-MAPK content (p38, JNK, ERK1/2), and sternohyoid isotonic contractile and endurance properties ex vivo after 6 weeks of $\mathrm{CH}$ in the presence or absence of chronic antioxidant supplementation with tempol or $\mathrm{N}$-acetyl cysteine (NAC). We tested the hypothesis that $\mathrm{CH}$ causes aberrant redox modulation of sternohyoid muscle function which is reversible by antioxidant supplementation.

\section{Materials and Methods}

\section{Ethical Approval}

All protocols involving animals described in this study were approved by local ethics committee and were performed under license from the Irish Government Department of Health and Children in accordance with EU legislation.

\section{Animal Model}

In the first series of experiments, 48 adult male C576Bl/J mice (Charles River Laboratories, UK) were exposed to 1,3, or 6 weeks of $\mathrm{CH}\left(\mathrm{FiO}_{2}=0.1\right)$ or normoxia (6 groups: $n=8$ per group, matched for age and weight) in environmental chambers (OxyCycler Model A84, BioSpherix Ltd, USA) with precise control of ambient oxygen concentration. All mice were housed at room 
temperature on a 12:12-h light-dark cycle. Food and water were available ad libitum, and the chambers were opened briefly once a week for cleaning. In a second series, 32 adult male C576Bl/J mice were exposed to normoxia or $\mathrm{CH}$ with or without antioxidant supplementation with tempol or NAC for 6 weeks (4 groups: $n=8$ per group, matched for age and weight). At the end of the gas treatment periods, animals were anesthetized by $5 \%$ isoflurane inhalation in oxygen and euthanized by cervical dislocation. Blood samples were taken in capillary tubes for hematocrit determination.

\section{Molecular Studies}

\section{Tissue Preparation for Molecular Studies}

Sternohyoid muscles were excised, snap frozen in liquid nitrogen and stored at $-80^{\circ} \mathrm{C}$. Frozen muscle samples were homogenized in $10 \% \mathrm{w} / \mathrm{v}$ modified radioimmunoprecipitation (RIPA) assay buffer (1X RIPA, $200 \mathrm{mM}$ sodium fluoride, $1 \mathrm{mM}$ phenylmethylsulfonyl fluoride, protease inhibitor cocktail, phosphatase inhibitor cocktail (Fisher Scientific, Ireland) and centrifuged at $13,000 \mathrm{~g}$ for $15 \mathrm{~min}$ to separate the insoluble fraction from crude protein homogenate. Protein concentrations were evaluated using a bicinchoninic assay (Pierce Biotechnology (Fisher Scientific), Ireland) against bovine serum albumin standards. Two additional muscles, the soleus and extensor digitorum longus (EDL), slow and fast fiber type limb muscles respectively, were also prepared in this manner for determination of total protein carbonyl and free thiol content for comparison to sternohyoid.

\section{Total Protein Carbonyl and Free Thiol Content}

As previously described (Cole et al., 2014; Hu et al., 2014; Rainville et al., 2014), muscle homogenates were incubated with either $2 \mathrm{mM}$ fluorescein-thiosemicarbazide (FTSC) or $2 \mathrm{mM}$ iodoacetamidofluorescein (IAF) (Sigma-Aldrich Co., Ireland) for $2 \mathrm{~h}$ in the dark on ice for detection of free protein carbonyl and thiol groups respectively. Samples were then precipitated with $20 \%$ trichloroacetic acid (TCA) in acetone, followed by centrifugation at $11,000 \mathrm{~g}$ for $3 \mathrm{~min}$. Protein pellets were then washed with ice-cold excess 1:1 ethylacetate/ethanol or acetone (for FTSC and IAF respectively) to remove excess TCA, interfering salts and non-protein contaminants. Samples were dried, re-suspended in sample buffer containing 5\% beta-mercaptoethanol and heated at $95^{\circ} \mathrm{C}$ for $5 \mathrm{~min}$ before electrophoretic separation on a $12 \%$ polyacrylamide gel (1D). Fluorescent images of the gels were captured on a Typhoon Trio+ Variable-Mode Imager (GE Healthcare, UK). Protein bands were visualized by colloidal coomassie staining (Dyballa and Metzger, 2009) and images were captured on a calibrating image densitometer (GS-800, Bio-Rad, USA).

\section{D Redox Proteomics}

As previously described (Cole et al., 2014; Hu et al., 2014; Rainville et al., 2014), this method separates proteins according to their isoelectric point and molecular mass such that they appear as spots when stained on polyacrylamide gels; protein spots can be analyzed independently. Briefly, sternohyoid muscle samples were treated as described above for 1D preparation until re-suspension in sample buffer. Samples were instead re-suspended in rehydration buffer (7 $\mathrm{M}$ urea, $2 \mathrm{M}$ thiourea, 2\% (w/v) 3-[(3-Cholamidopropyl)dimethylammonio]1-propanesulfonate, 4\% (v/v) ampholytes (Pharmalyte 3-10, Amersham, UK), 1\% (v/v) destreak reagent (Amersham) and a trace amount of bromophenol blue) and loaded onto $70 \mathrm{~mm}$ pH 3-10 non-linear immobilized pH gradient (IPG) strips (GE Healthcare) overnight. IPG strips were focused on a Protean isoelectric focusing (IEF) cell (BioRad) with linear voltage increases: $250 \mathrm{~V}$ for $15 \mathrm{~min}$; $4000 \mathrm{~V}$ for $2 \mathrm{~h}$; then up to $20,000 \mathrm{~V}$. Following IEF, strips were equilibrated $(20 \mathrm{~min})$ in equilibration buffer (6 $\mathrm{M}$ urea, $0.375 \mathrm{M}$ Tris, $\mathrm{pH} 8.8,2 \%(\mathrm{w} / \mathrm{v})$ sodium-dodecyl sulfate, and $20 \%(\mathrm{v} / \mathrm{v})$ glycerol) containing $2 \%(\mathrm{w} / \mathrm{v})$ dithiothreitol, and then for $20 \mathrm{~min}$ in equilibration buffer containing $2.5 \%$ $(\mathrm{w} / \mathrm{v})$ iodoacetamide. Equilibrated strips were then subjected to gel electrophoresis. Fluorescent and colloidal coomassie stained gel images were captured as described above.

\section{Image Analysis}

Quantity One image analysis software (Bio-Rad) was used to subtract background and quantify optical density for total protein carbonyl and free thiol content. For each sample, intensity of fluorescence was normalized to intensity of coomassie staining. For 2D separations, alignment of gels, spot matching, and quantification of spot volumes was carried out using Progenesis SameSpots image analysis software (Version 4.5; Non-linear Dynamics, USA).

\section{Protein Digestion and Identification}

Gel spots were used for in-gel protein digestion with trypsin. The extracted peptides were loaded onto a R2 micro column (RP-C18 equivalent) where they were desalted, concentrated and eluted directly onto a MALDI plate using $\alpha$-cyano-4-hydroxycinnamic acid $(5 \mathrm{mg} / \mathrm{ml})$ as matrix solution in $50 \%(\mathrm{v} / \mathrm{v})$ acetonitrile and $5 \%(\mathrm{v} / \mathrm{v})$ formic acid. Mass spectra of the peptides were acquired with positive reflectron mass spectrometry (MS) and MS/MS modes using MALDI-TOF/TOF MS instrument (4800 plus MALDI TOF/TOF analyzer). The collected MS and MS/MS spectra were analyzed in combined mode using Mascot (version 2.2; Matrix Science, Boston, MA) search engine and SwissProt (release 02_2013, 539,165 entries) database restricted to $50 \mathrm{ppm}$ peptide mass tolerance for the parent ions, an error of $0.3 \mathrm{Da}$ for the fragments, one missed cleavage in peptide masses, and carbamidomethylation of Cys and oxidation of Met as fixed and variable amino acid modifications, respectively. No taxonomy restrictions were applied. The identified proteins were only considered if a MASCOT score above $95 \%$ confidence was obtained $(p<0.05)$ and at least one peptide was identified with a score above $95 \%$ confidence $(p<0.05)$. This analysis was conducted by the Analytical Services Unit, Instituto de Tecnologia Química e Biológica (ITQB), New University of Lisbon, Lisbon, Portugal.

\section{Chymotrypsin-like Proteasome Activity}

Chymotrypsin-like activity of the $20 \mathrm{~S}$ proteasome was measured fluorometrically in accordance with the manufacturer's instructions (Abcam, UK). 


\section{Glycolytic Enzyme Activities}

For GAPDH activity measurement, samples were added to $13.5 \mathrm{mM}$ sodium pyrophosphate buffer ( $\mathrm{pH} 8.5$ ) containing $30 \mathrm{mM}$ sodium arsenate, $0.25 \mathrm{mM}$ NAD with $3.325 \mathrm{mM}$ DTT. Samples were incubated at $25^{\circ} \mathrm{C}$ for $10 \mathrm{~min}$ to achieve temperature equilibration and to establish a blank rate, if any. $0.5 \mathrm{mM}$ DL-glyceraldehdye-3-phosphate was added and absorbance was recorded for $10 \mathrm{~min}$ at $339 \mathrm{~nm}$. Measured rates were corrected by measuring the blank rate of the reaction. One unit is defined as $1 \mu \mathrm{mol} \mathrm{NADH}$ generated/minute/mg protein. Similarly, total $\mathrm{LDH}$ activity was calculated as rate of absorbance at $339 \mathrm{~nm}$ produced by oxidation of $\mathrm{NADH}$ at $25^{\circ} \mathrm{C}$ and $\mathrm{pH} 7.3$ in $0.2 \mathrm{M}$ Tris-HCL buffer containing $1 \mathrm{mM}$ sodium pyruvate and $0.22 \mathrm{mM}$ NADH.

\section{HIF-1 $\alpha$ and Phospho-MAPK Content}

HIF- $1 \alpha$ content and phospho-(p)-p38, p-JNK, p-ERK1/2 content were assayed by an immuno-linked luminescence assay in accordance with manufacturer's instructions (Mesoscale Discovery, Gaithersburg, USA). HeLa cells treated with and without cobalt chloride for $16 \mathrm{~h}$ provided positive and negative controls respectively for the HIF- $1 \alpha$ assay. Lysate from Jurkat cells treated with $1 \mathrm{~mol}$ rapamycin for $3 \mathrm{~h}$ to activate MAPK phosphatase 1 was used as negative control for the MAPK assay. Lysate from Jurkat cells treated with $50 \mathrm{nM}$ calyculin A and $200 \mathrm{nM}$ PMA for 15 min to stimulate phosphorylation of MAPK proteins was used as a positive control (Mesoscale Discovery).

\section{Isotonic Muscle Function Ex Vivo Muscle Preparation}

Animals were anesthetized by $5 \%$ isoflurane inhalation in air and euthanized by cervical dislocation. Sternohyoid muscles were excised and placed in a bath of Krebs solution $(\mathrm{NaCl} 120 \mathrm{mM}$, $\mathrm{KCl} 5 \mathrm{mM}, \mathrm{Ca}^{2+}$ gluconate $2.5 \mathrm{mM}, \mathrm{MgSO}_{4} 1.2 \mathrm{mM}, \mathrm{NaH}_{2} \mathrm{PO}_{4}$ $1.2 \mathrm{mM}, \mathrm{NaHCO}_{3} 25 \mathrm{mM}$, glucose $11.5 \mathrm{mM}$, and $25 \mu \mathrm{M} \mathrm{d}-$ tubocurarine) at room temperature and gassed with carbogen $\left(95 \% \mathrm{O}_{2} / 5 \% \mathrm{CO}_{2}\right)$ before mounting in the test bath for assessment of muscle contractile and endurance performance. Whole intact mouse sternohyoid muscle bundles were arranged between the electrodes with the sternum anchored at a fixed base and hyoid bone connected by a non-elastic string to a dual-mode lever force transducer (Aurora Scientific, Canada) such that fibers were orientated vertically. Upon placement in the test bath, bundles were incubated at $35^{\circ} \mathrm{C}$ in Krebs solution gassed with carbogen $\left(95 \% \mathrm{O}_{2} / 5 \% \mathrm{CO}_{2}\right)$. Muscle performance has previously been shown (Skelly et al., 2010) to be optimal under hyperoxic conditions $\left(95 \% \mathrm{O}_{2}\right)$ compared to normoxic conditions $\left(21 \% \mathrm{O}_{2}\right)$. Bundles were equilibrated for $5 \mathrm{~min}$ in gassed Krebs solution prior to initiating the experimental protocol.

\section{Protocol}

Bundles were set to optimum length (Lo-length at which peak twitch force occurs) by adjusting the position of the force transducer with a micro-positioner and stimulating with repeated single pulses whilst adjusting muscle length until peak twitch force was reached. Contractile kinetics [time to peak (TTP) and half-relaxation time (T50)] were measured from the peak twitch force recordings. After $5 \mathrm{~min}$ of equilibration, the lever of the force transducer was set to maximum rigidity $(\sim 500 \mathrm{mN} ;>100 \%$ load) and a tetanic contraction was elicited by stimulating the bundle with supra-maximal voltage at $100 \mathrm{~Hz}$ for $300 \mathrm{~ms}$. The peak isometric force (Fmax) was established allowing determination of $100 \%$ load for isotonic assessments. Shortening contractions were elicited in incremental steps ranging from 0 to $100 \%$ load with 1 min rest between each step. Peak shortening velocity (Vmax) was determined during the initial $30 \mathrm{~ms}$ of shortening (see Figure 1) as this is when velocity is greatest (Watchko et al., 1997; Van Lunteren et al., 2007; Van Lunteren and Pollarine, 2010). Power was determined at each step as the product of force/cross-sectional area (CSA) $x$ shortening velocity/Lo. Peak specific work (Wmax) was calculated as force/CSA $x$ shortening $(\mathrm{L} / \mathrm{Lo})$ at the load where the product of these variables was greatest.

\section{Isotonic Function Data Analysis}

Muscle cross-sectional area (CSA) was calculated as the blotted dry muscle bundle weight divided by the product of Lo and the specific density which was assumed to be $1.056 \mathrm{~g} / \mathrm{cm}^{3}$. Specific force was calculated as $\mathrm{N} / \mathrm{cm}^{2}$. Specific shortening velocity was calculated as Lo/s. Specific power was calculated as Watts $/ \mathrm{cm}^{2}$. Wmax was calculated as Joules $/ \mathrm{cm}^{3}$.

\section{Statistical Analyses}

Statistical comparisons of the total mean fluorescence intensity for 1D preparations and FTSC/IAF- and coomassie-labeled spot volumes (2D) were measured using Student $t$-tests, MannWhitney $U$-tests, or One-Way ANOVA as appropriate after testing for normality and equal variance in the data sets. Student $t$-test or Mann-Whitney $U$-test was used as appropriate to compare control and $\mathrm{CH}$ groups for chymotrypsin-like activity of the $20 \mathrm{~S}$ proteasome, and GAPDH and LDH activities. Tissue limitations restricted the measurement of all molecular components at all three time points of $\mathrm{CH}$ exposure. HIF- $1 \alpha$ content and p-MAPK contents were compared between groups by One-Way

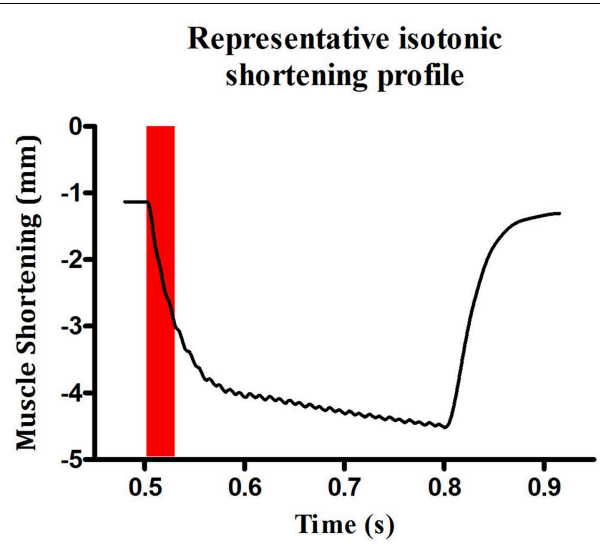

FIGURE 1 | Representative profile of sternohyoid peak shortening velocity. An original record illustrating a representative contraction at $0 \%$ load. Maximum velocity of shortening was calculated during the first $30 \mathrm{~ms}$ of the contraction. 
ANOVA followed by Tukey's multiple comparison post-hoc test, or the Kruskal-Wallis test followed by Dunn's multiple comparison post-hoc test as appropriate, after testing for normality and equal variance in the data sets. Statistical comparisons were performed between groups for sternohyoid contractile and endurance performance using One-Way ANOVA followed by Tukey's multiple comparison post-hoc tests. Power-load relationship was assessed by Two-Way ANOVA followed by Bonferroni's post-hoc multiple comparison tests. Linear regression analysis was performed to assess the relationship between oxidative stress markers (protein free thiol and carbonyl groups) and sternohyoid muscle power. $P<0.05$ was the criterion for statistical significance in all tests.

\section{Results}

\section{Animal Model}

Hematocrit was significantly $(p<0.001)$ increased by $\mathrm{CH}$ exposure (Table 1). Antioxidant supplementation in animals exposed to 6 weeks of $\mathrm{CH}$ had no effect on hematocrit compared to $\mathrm{CH}$ alone. Animals drank equivalent volumes of water (with or without antioxidant) per day. Body mass decreased after 1 week of $\mathrm{CH}$ exposure but all hypoxic animals returned to a growth curve equivalent to the control animals for weeks two through to six of the gas treatments (data not shown).

\section{Total Protein Carbonyl and Free Thiol Content}

Significant increases in sternohyoid carbonyl content were observed after $3(p<0.001)$ and $6(p<0.001)$ weeks of $\mathrm{CH}$ (Figure 2A) - indicative of increased sternohyoid protein oxidation. Sternohyoid protein free thiol content changes were bi-phasic (Figure 2B). There was a significant increase in sternohyoid protein free thiol content after $1(p<0.05)$ and 3 $(p<0.01)$ weeks of $\mathrm{CH}$; however free thiol content was significantly lower than control after 6 weeks of $\mathrm{CH}(p<0.001)$. For comparison, two limb muscles, namely soleus, and extensor digitorum longus (EDL) were also studied. Unlike the sternohyoid, there were no significant changes to the carbonyl content of the EDL proteome after $\mathrm{CH}$ exposure (Figure 3A). There was, however, significant increases in EDL free thiol content after 1 $(p<0.01), 3(p<0.001)$, and $6(p<0.001)$ weeks of $\mathrm{CH}-$ though the magnitude of the increase is seen to decrease over time (Figure 3B). Similar to the sternohyoid muscle, but unlike the EDL, significant increases in soleus protein carbonyl content were observed after $3(p<0.05)$, and $6(p<0.01)$ weeks of $\mathrm{CH}$

TABLE 1 | Hematocrit values after 1, 3, or 6 weeks of normoxia or chronic sustained hypoxia $(\mathrm{CH})$.

\begin{tabular}{lccc}
\hline & Normoxia & CH & $P$-value \\
\hline HEMATOCRIT (\%) & & & \\
One Week & $34 \pm 2$ & $52 \pm 2$ & $P<0.001$ \\
Three Weeks & $38 \pm 1$ & $65 \pm 1$ & $P<0.001$ \\
Six Weeks & $32 \pm 1$ & $62 \pm 1$ & $P<0.001$ \\
\hline
\end{tabular}

Data are presented as mean $\pm S E M ; n=8$ per group. ${ }^{a}$ Student unpaired t-test.
(Figure 4A). Soleus protein free thiol content was significantly increased after $1(p<0.001), 3(p<0.01)$, and $6(p<0.001)$ weeks of $\mathrm{CH}$ compared to controls (Figure 4B). Consistent with EDL, there was a decline in increased free thiol content in the soleus with progressive $\mathrm{CH}$.

\section{D Redox Proteomics}

In the sternohyoid, 498, 264, and 996 resolved spots were matched in FTSC-, IAF-labeled and coomassie-stained separations respectively. A significant relative volume difference was observed in 87 FTSC, 51 IAF, and 156 coomassie spots comparing control and $\mathrm{CH}$ groups $(p<0.05)$. Proteins were selected for mass spectrometry analysis based on separation, resolution, abundance, and overlap in fluorescence-stain and muscle separations. Protein smears and gel defects were excluded. Results for protein remodeling are presented in Table 2 with proteins grouped according to cellular location and/or function. Selected spots can be visualized on the representative coomassie stained gel shown in Figure 5. A change in FTSC and IAF fluorescence

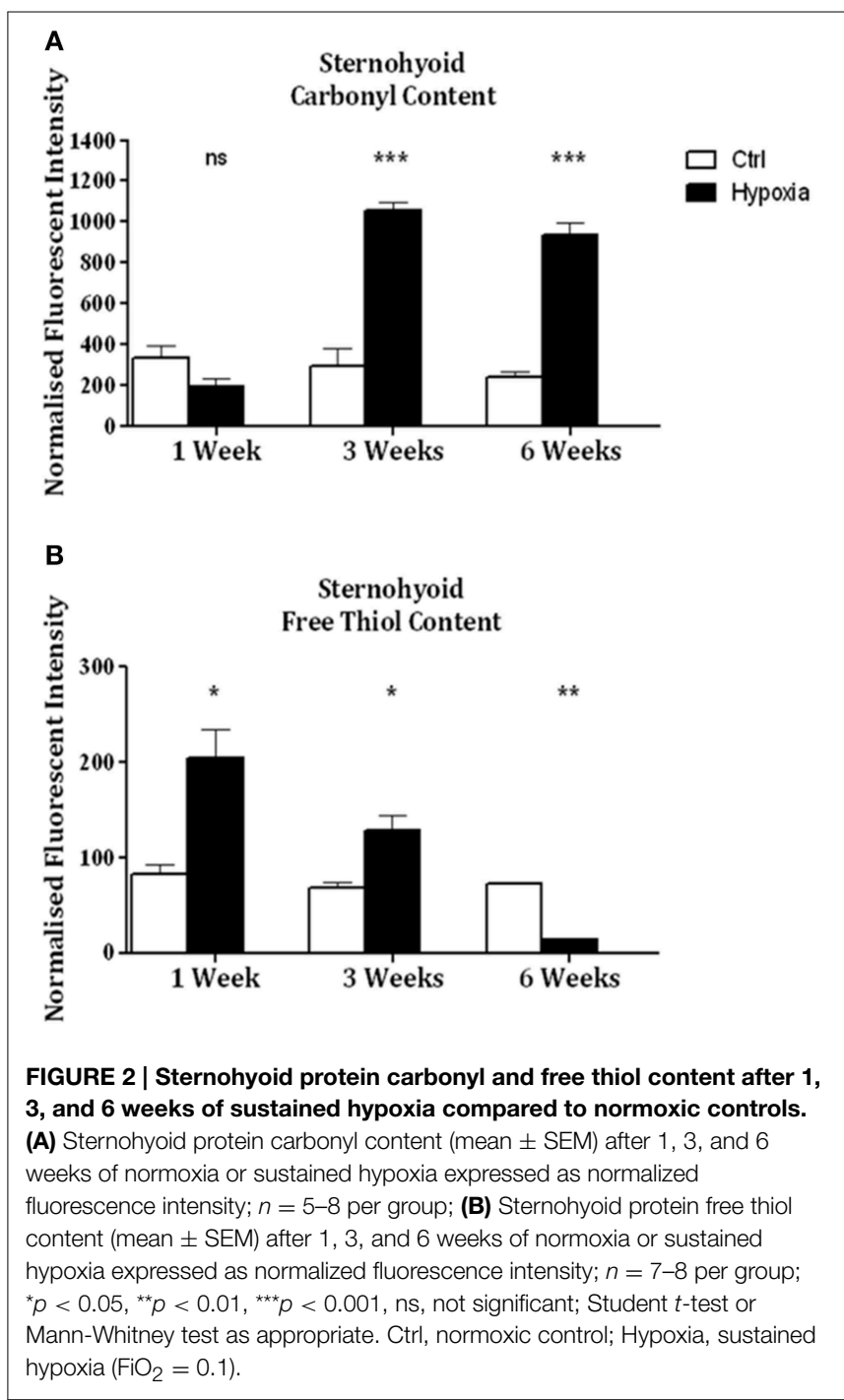




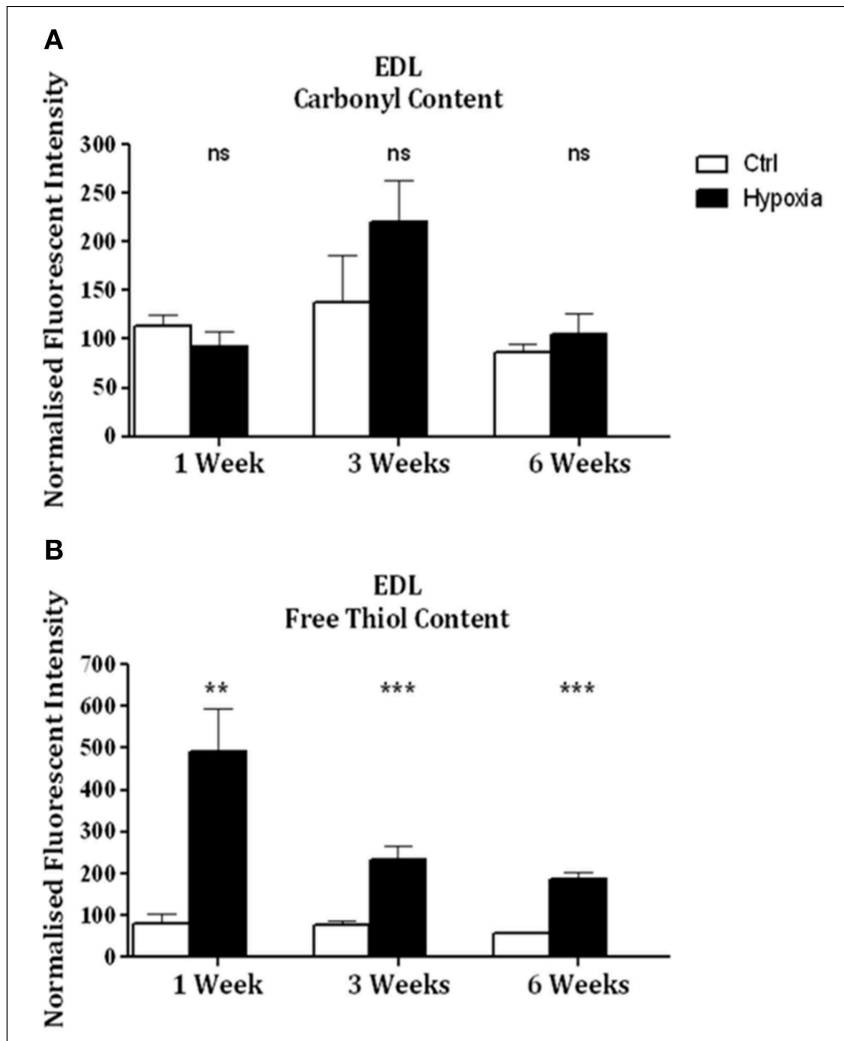

FIGURE 3 | EDL protein carbonyl and free thiol content after 1, 3, and 6 weeks of sustained hypoxia compared to normoxic controls. (A) EDL protein carbonyl content (mean \pm SEM) after 1, 3, and 6 weeks of sustained hypoxia expressed as normalized fluorescence intensity; $n=4-8$ per group; (B) EDL protein free thiol content (mean \pm SEM) after 1, 3, and 6 weeks of sustained hypoxia expressed as normalized fluorescence intensity; $n=6-8$ per group; ${ }^{\star *} p<0.01,{ }^{\star \star *} p<0.001$, ns, not significant; Student $t$-test or Mann-Whitney test as appropriate; Ctrl, normoxic control; Hypoxia, sustained hypoxia $\left(\mathrm{FiO}_{2}=0.1\right)$. intensity signal independent of, or differential to, coomassie signal is indicative of protein redox remodeling.

\section{Sternohyoid Glycolytic Enzyme Activities}

Sternohyoid GAPDH activity was significantly increased after 1 week of $\mathrm{CH}(p<0.05)$ but significantly decreased after 3 weeks of $\mathrm{CH}(p<0.01)$ (data not shown). LDH activity in the sternohyoid (data not shown) was significantly increased after 1 week of $\mathrm{CH}(p<0.05)$.

\section{Sternohyoid Chymotrypsin-like Proteasome Activity}

Chymotrypsin-like proteasome activity was unchanged in the sternohyoid after 6 weeks of $\mathrm{CH}$ (data not shown).

\section{Sternohyoid HIF-1 $\alpha$ Content}

There was no change in sternohyoid HIF-1 $\alpha$ content following 6 weeks of $\mathrm{CH}$ with or without antioxidant supplementation (data not shown).
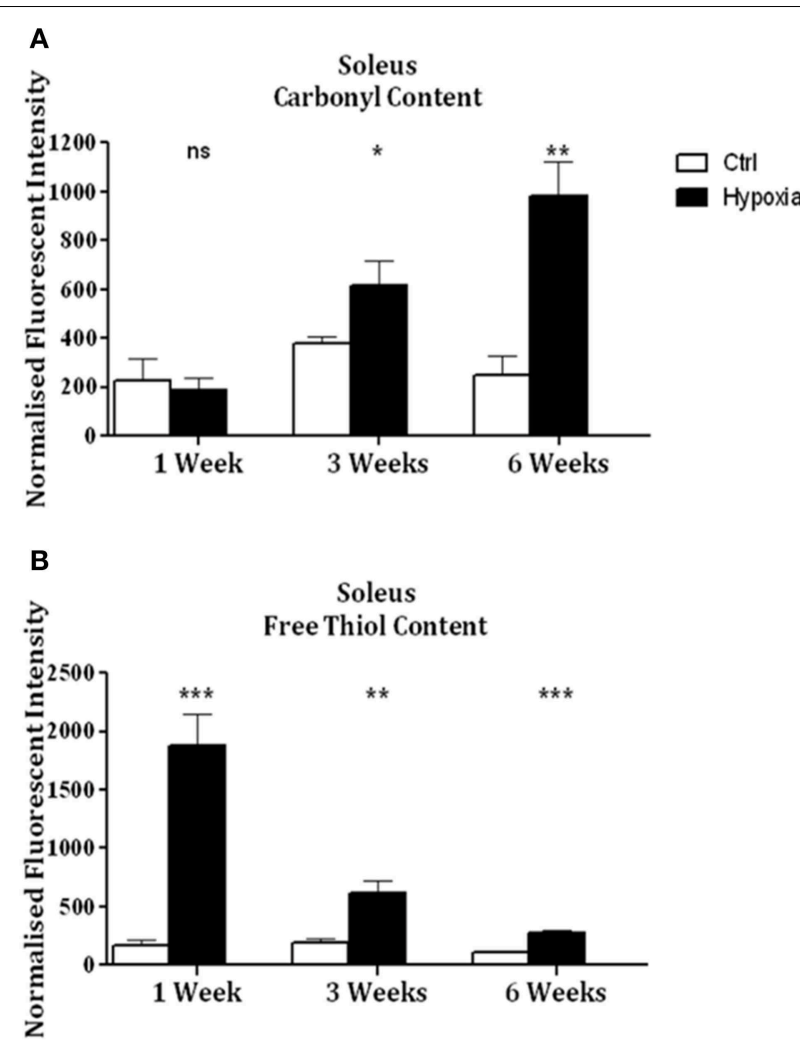

FIGURE 4 | Soleus protein carbonyl and free thiol content after 1, 3, and 6 weeks of sustained hypoxia compared to normoxic controls. (A) Soleus protein carbonyl content (mean \pm SEM) after 1,3 , and 6 weeks of sustained hypoxia expressed as normalized fluorescence intensity; $n=4-8$ per group; (B) Soleus protein free thiol content (mean \pm SEM) after 1, 3, and 6 weeks of sustained hypoxia expressed as normalized fluorescence intensity; $n=8$ per group; ${ }^{\star} p<0.05,{ }^{\star \star} p<0.01,{ }^{\star \star *} p<0.001$, ns, not significant; Student $t$-test or Mann-Whitney test as appropriate; Ctrl, normoxic control; Hypoxia, sustained hypoxia $\left(\mathrm{FiO}_{2}=0.1\right)$.

\section{Sternohyoid Phospho-MAPK Content}

There was no change in sternohyoid p-p38 content following 6 weeks of $\mathrm{CH}$ with or without antioxidant supplementation (Figure 6A). However, 6 weeks of $\mathrm{CH}$ significantly decreased sternohyoid p-JNK content compared to control (One-Way ANOVA $(p<0.01)$ followed by Tukey's multiple comparison test $(p<0.05)$; chronic antioxidant supplementation with either tempol or NAC did not prevent this (Figure 6B). A similar effect was observed for sternohyoid p-ERK1/2 content. A Kruskal-Wallis test revealed a significant difference in the mean values of the groups. However, Dunn's multiple comparisons test revealed no significant differences between pairs (Figure 6C).

\section{Sternohyoid Protein Carbonyl and Free Thiol Content after Antioxidant Treatment}

In the second cohort of animals, significant increases in sternohyoid protein carbonyl content were again observed after 6 weeks of $\mathrm{CH}(p<0.001)$. Chronic antioxidant supplementation with either Tempol $(p<0.001)$ or NAC $(p<0.001)$ significantly ameliorated the $\mathrm{CH}$-induced increase in protein carbonyl content 
TABLE 2 | Identifications by mass spectrometry of proteins undergoing significant redox remodeling in the sternohyoid muscle after 6 weeks of sustained hypoxia.

\begin{tabular}{|c|c|c|c|c|c|c|c|c|c|}
\hline Spot \# & Protein & Mw (Da) & GI number & $\begin{array}{c}\text { Mascot } \\
\text { score }\end{array}$ & $\begin{array}{l}\text { Matched } \\
\text { peptides }\end{array}$ & $\begin{array}{l}\text { Sequence } \\
\text { coverage }\end{array}$ & $\begin{array}{l}\text { Carbonyl } \\
\text { p-value, } \\
\text { fold }\end{array}$ & $\begin{array}{l}\text { Free thiol } \\
\text { p-value, } \\
\text { fold }\end{array}$ & $\begin{array}{c}\text { Expression } \\
\text { p-value, } \\
\text { fold }\end{array}$ \\
\hline \multicolumn{10}{|c|}{ ELECTRON TRANSPORT CHAIN } \\
\hline 1 & Cytochrome bc - 1 complex subunit 1 & 52,819 & 341941780 & 430 & 6 & $26 \%$ & - & $<0.01,-1.4$ & $<0.001,-2$ \\
\hline 2 & ATP Synthase subunit $\alpha$ & 59,716 & 416677 & 997 & 6 & $53 \%$ & - & - & $<0.01,+1.5$ \\
\hline \multicolumn{10}{|c|}{ TCA CYCLE } \\
\hline 3 & Aconitase hydratase & 85,410 & 60391212 & 1210 & 11 & $41 \%$ & $<0.01,+1.4$ & $<0.001,-2$ & $<0.01,-2.6$ \\
\hline 4 & 2-oxo-glutarate dehydrogenase, $\mathrm{mt}$ & 116,375 & 146345472 & 477 & 4 & $22 \%$ & - & $<0.01,-2.4$ & $<0.01,+2.8$ \\
\hline \multicolumn{10}{|c|}{ GLYCOLYSIS } \\
\hline 5 & Fructose bis-phosphate aldolase A & 39,331 & 113607 & 588 & 3 & $70 \%$ & - & $<0.01,-2.9$ & - \\
\hline 6 & Glyceraldehyde-3-phosphate dehydrogenase & 35,787 & 120702 & 531 & 4 & $48 \%$ & - & $<0.01,-1.6$ & $<0.001,-2$ \\
\hline 7 & Phosphoglycerate kinase 1 & 44,534 & 1730519 & 534 & 4 & $45 \%$ & - & - & $<0.01,+1.7$ \\
\hline 8 & Phosphoglycerate mutase 2 & 28,809 & 6093745 & 1010 & 9 & $57 \%$ & - & - & $<0.01,+1.7$ \\
\hline 9 & Pyruvate kinase isozymes M1/M2 & 57,305 & 146345448 & 837 & 6 & $53 \%$ & $<0.01,-1.2$ & - & $<0.01,+1.3$ \\
\hline \multicolumn{10}{|c|}{ PHOSPHAGEN AND LIPID METABOLISM } \\
\hline 10 & Glycerol-3-phosphate dehydrogenase [NAD(+)] & 37,548 & 121557 & 412 & 3 & $48 \%$ & - & $<0.01,-2$ & $<0.01,-2.6$ \\
\hline 11 & Creatine kinase m-type & 43,014 & 124056470 & 784 & 7 & $42 \%$ & $<0.01,+1.2$ & - & $<0.01,-1.2$ \\
\hline \multicolumn{10}{|c|}{ STRESS RESPONSE AND IRON HOMEOSTASIS } \\
\hline 12 & Glycogen phosphorylase & 97,225 & 14916635 & 1450 & 13 & $47 \%$ & $<0.01,-1.3$ & - & $<0.01,+4.1$ \\
\hline 13 & 90kDa heat shock protein & 83,229 & 341941065 & 742 & 6 & $31 \%$ & - & - & $<0.01,-1.3$ \\
\hline 14 & Alpha crystallin B chain & 20,056 & 6166129 & 761 & 7 & $65 \%$ & $<0.01,+1.2$ & - & - \\
\hline 15 & Myoglobin & 17,059 & 127676 & 923 & 7 & $43 \%$ & - & - & $<0.01,-1.7$ \\
\hline 16 & Serotransferrin & 76,674 & 21363012 & 121 & 1 & $17 \%$ & $<0.01,-1.4$ & $<0.01,+1.8$ & - \\
\hline 17 & Carbonic anhydrase III & 29,348 & 30581036 & 966 & 8 & $71 \%$ & $<0.01,+1.2$ & $<0.01,-2.7$ & $<0.01,+1.9$ \\
\hline 18 & Albumin & 68,648 & 5915682 & 1340 & 11 & $53 \%$ & - & - & $<0.01,-1.8$ \\
\hline \multicolumn{10}{|c|}{ CROSS-BRIDGE AND SARCOPLASMIC RETICULUM } \\
\hline 19 & Calsequestrin & 46,420 & 341940315 & 543 & 4 & $19 \%$ & $<0.01,-1.5$ & - & $<0.01,-2.3$ \\
\hline
\end{tabular}

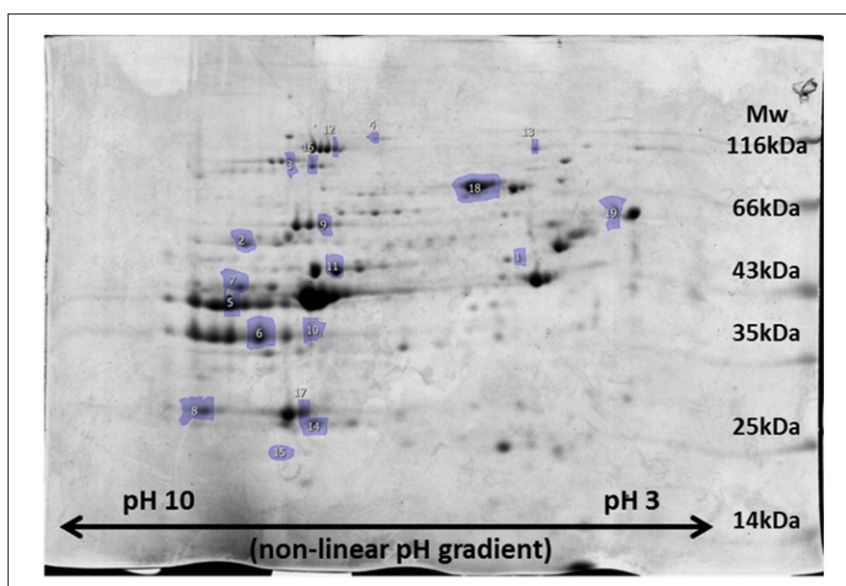

FIGURE 5 | Representative image of 2D-PAGE sternohyoid muscle protein profile after coomassie staining of proteins. A molecular mass marker ranging from 14 to $116 \mathrm{kDa}$ is shown for size reference and isoelectric point is indicated along the range $\mathrm{pH} 10-3$. Spot numbers match those presented in Table 2.

(Figure 7A). Similarly, sternohyoid protein free thiol content was significantly lower than control after 6 weeks of $\mathrm{CH}(p<0.01)$ and antioxidant treatment with Tempol $(p<0.001)$ and NAC $(p<0.05)$ ameliorated this effect (Figure 7B).

\section{Sternohyoid Muscle Function}

There are no significant differences observed across groups for contractile kinetics, twitch force, Vmax, Wmax, or isotonic fatigue index (Table 3) as determined by One-Way ANOVA or Kruskal-Wallis test; however, $\mathrm{CH}$ exposure increased the contraction time, and decreased endurance (Table 3). NAC supplementation in $\mathrm{CH}$ increased peak twitch force, Vmax, Wmax, and endurance (Table 3). Fmax is significantly different across groups; decreased in $\mathrm{CH}$ compared to control and significantly increased by NAC supplementation in $\mathrm{CH}$ compared to $\mathrm{CH}$ alone as revealed by Tukey's multiple comparison post-hoc test (Table 3).

Sternohyoid muscle isotonic contractile function (power) was significantly depressed by $\mathrm{CH}$ exposure (Figure 8; Two-Way ANOVA: gas treatment: $p<0.001)$. Significant correlations were observed for oxidative stress markers and sternohyoid muscle function (Figure 9). The deleterious effects of $\mathrm{CH}$ exposure on sternohyoid function were prevented with antioxidant supplementation in $\mathrm{CH}$ using either tempol or NAC (Figure 8).

\section{Discussion}

This is the first study to identify proteins in an upper airway muscle undergoing redox remodeling following exposure to $\mathrm{CH}$. $\mathrm{CH}$ decreased sternohyoid force- and power-generating 


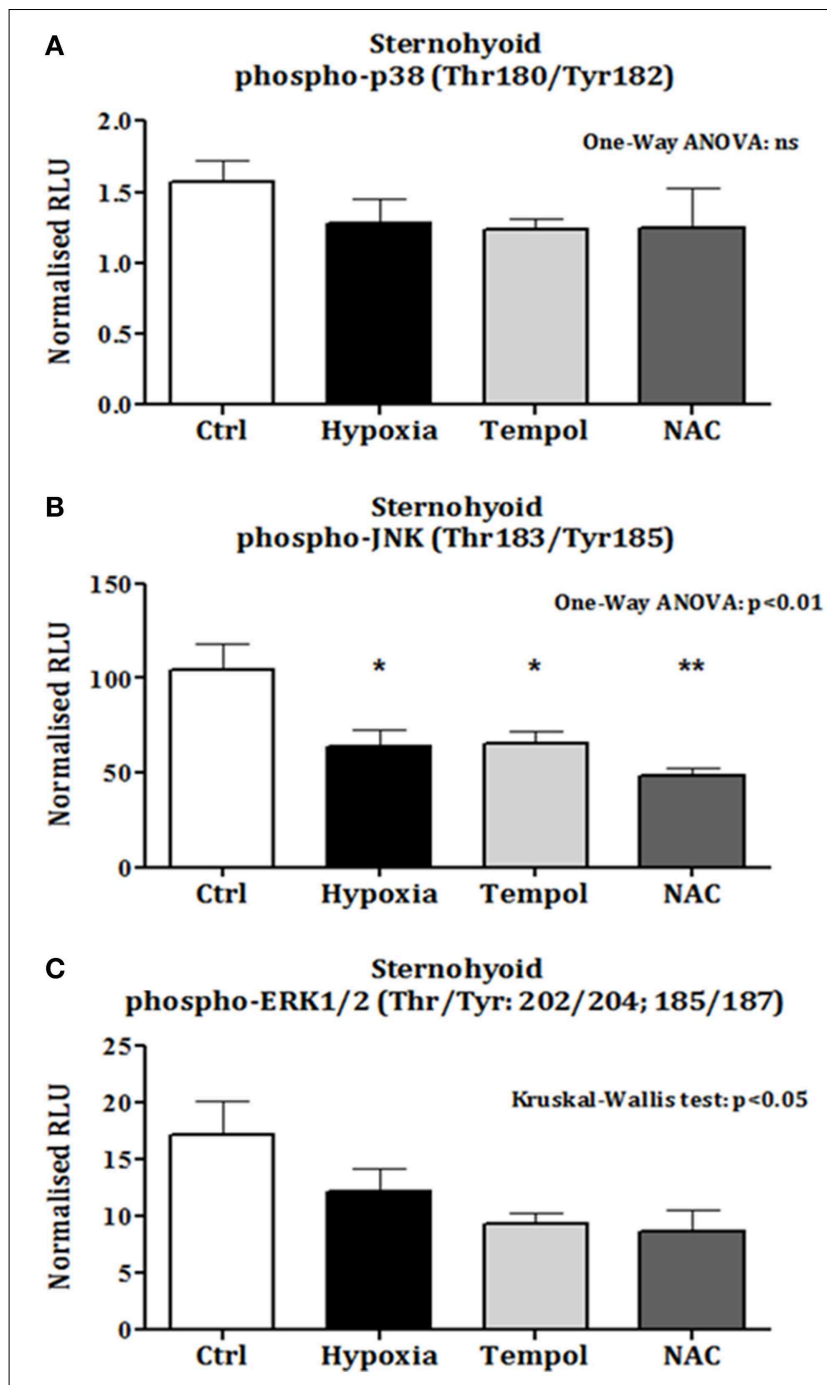

FIGURE 6 | Sternohyoid phospho-MAPK contents after 6 weeks of normoxia and sustained hypoxia \pm chronic antioxidant supplementation. (A) Sternohyoid phospho-p38 content (mean \pm SEM) expressed as normalized relative luminescence units; $n=5-7$ per group; (B) Sternohyoid phospho-JNK content (mean \pm SEM expressed as normalized relative luminescence units; $n=5-7$ per group; (C) Sternohyoid phospho-ERK $1 / 2$ content (mean \pm SEM) expressed as normalized relative luminescence units; $n=5-7$ per group; ${ }^{*} p<0.05$ and ${ }^{* *} p<0.01$ vs. control, Tukey's multiple comparison test; Ctrl, normoxic control; Hypoxia, sustained hypoxia $\left(\mathrm{FiO}_{2}=\right.$ 0.1); Tempol, tempol + sustained hypoxia; NAC, NAC + sustained hypoxia; $\mathrm{RLU}$, relative luminescence units.

capacity. Antioxidant supplementation prevented $\mathrm{CH}$-induced sternohyoid dysfunction. The main findings of this study are: (1) $\mathrm{CH}$ induces temporal changes in protein carbonylation and free thiol oxidation in the sternohyoid, responses different to that seen in limb muscles; (2) Proteins key to muscle contraction, metabolism, and homeostasis are redox-modified in the sternohyoid following 6 weeks of $\mathrm{CH}$; (3) Glycolytic enzyme activities are temporally affected in the sternohyoid following progressive $\mathrm{CH}$ exposure; (4) $\mathrm{CH}$ has no effect on sternohyoid HIF- $1 \alpha$ content; (5) $\mathrm{CH}$ decreases p-JNK in sternohyoid

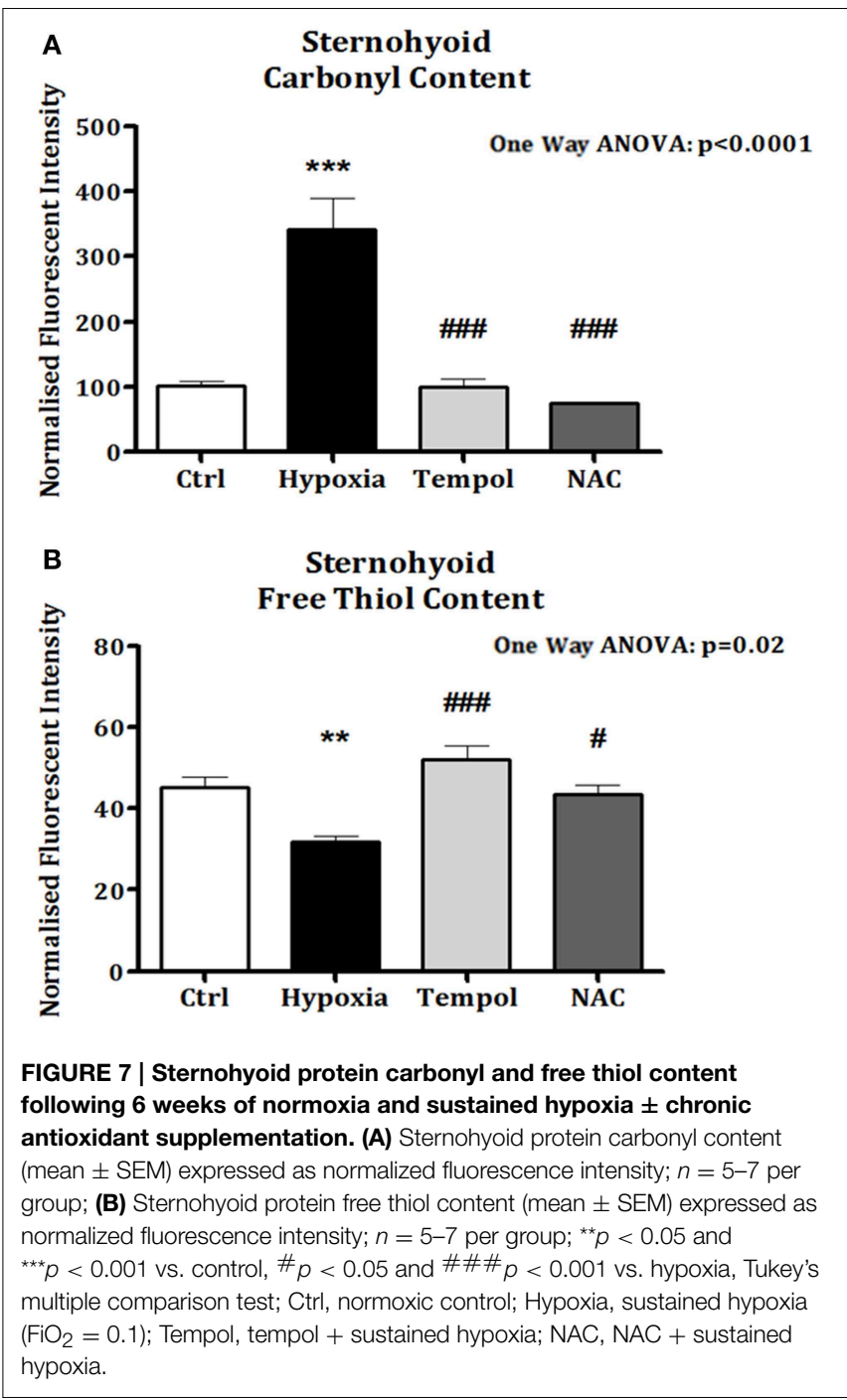

independent of antioxidant status; (6) $\mathrm{CH}$ causes sternohyoid muscle dysfunction; (7) Oxidative stress markers and muscle function were significantly correlated; (8) Both protein oxidation and contractile impairment following $\mathrm{CH}$ are fully reversed by chronic antioxidant supplementation.

\section{Muscle Redox Status}

In skeletal muscle adaptation to high altitude and respiratory diseases featuring hypoxia, ROS have been shown to cause protein redox remodeling and to modify protein function with resultant changes in metabolic processes, homeostasis and contractile performance (Zuo and Clanton, 2005; Marin-Corral et al., 2009; Murray, 2009; Chaudhary et al., 2012; Levine et al., 2013; Puig-Vilanova et al., 2015). However, the cause and motive for increased ROS production is unclear and may differ in skeletal muscles given their varied functional roles. In the present study, we observed time-dependent increases in protein oxidation (both increased carbonyl content and decreased free thiol content) in $\mathrm{CH}$-exposed sternohyoid muscle (differential to responses in limb muscles, which is likely pivotal for time-dependent and 
TABLE 3 | Sternohyoid muscle contractile properties after 6 weeks of normoxia and sustained hypoxia \pm chronic antioxidant supplementation.

\begin{tabular}{|c|c|c|c|c|c|}
\hline & Normoxia & Hypoxia & Tempol & NAC & $P$-Value ${ }^{a}$ \\
\hline TTP (ms) & $9 \pm 0$ & $10 \pm 0$ & $11 \pm 1$ & $10 \pm 0$ & ns \\
\hline T50 (ms) & $11 \pm 1$ & $11 \pm 1$ & $14 \pm 3$ & $12 \pm 2$ & ns \\
\hline $\mathrm{Pt}\left(\mathrm{N} / \mathrm{cm}^{2}\right)$ & $2.5 \pm 0.4$ & $1.6 \pm 0.2$ & $1.9 \pm 0.2$ & $3.0 \pm 0.9$ & ns \\
\hline $\mathrm{Fmax}\left(\mathrm{N} / \mathrm{cm}^{2}\right)$ & $12.3 \pm 1.5$ & $8.0 \pm 0.6^{*}$ & $11.0 \pm 0.3$ & $16.0 \pm 2.3^{\# \#}$ & $<0.01$ \\
\hline Vmax (Lo/s) & $5.4 \pm 0.7$ & $5.2 \pm 0.9$ & $6.1 \pm 0.7$ & $6.1 \pm 0.4$ & $\mathrm{~ns}$ \\
\hline$W \max \left(\mathrm{J} / \mathrm{cm}^{3}\right)$ & $0.6 \pm 0.1$ & $0.6 \pm 0.1$ & $0.8 \pm 0.1$ & $0.9 \pm 0.1$ & ns \\
\hline Fatigue Index (\% of initial power) & $63 \pm 14$ & $36 \pm 7$ & $33 \pm 11$ & $46 \pm 12$ & ns \\
\hline
\end{tabular}

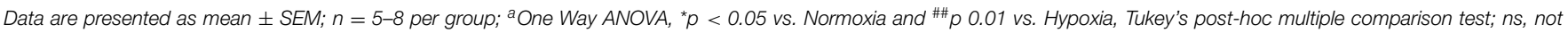
significant; Hypoxia, 6 weeks of sustained hypoxia $\left(\mathrm{FiO}_{2}=0.1\right)$; Tempol, tempol + hypoxia; NAC, NAC + hypoxia.

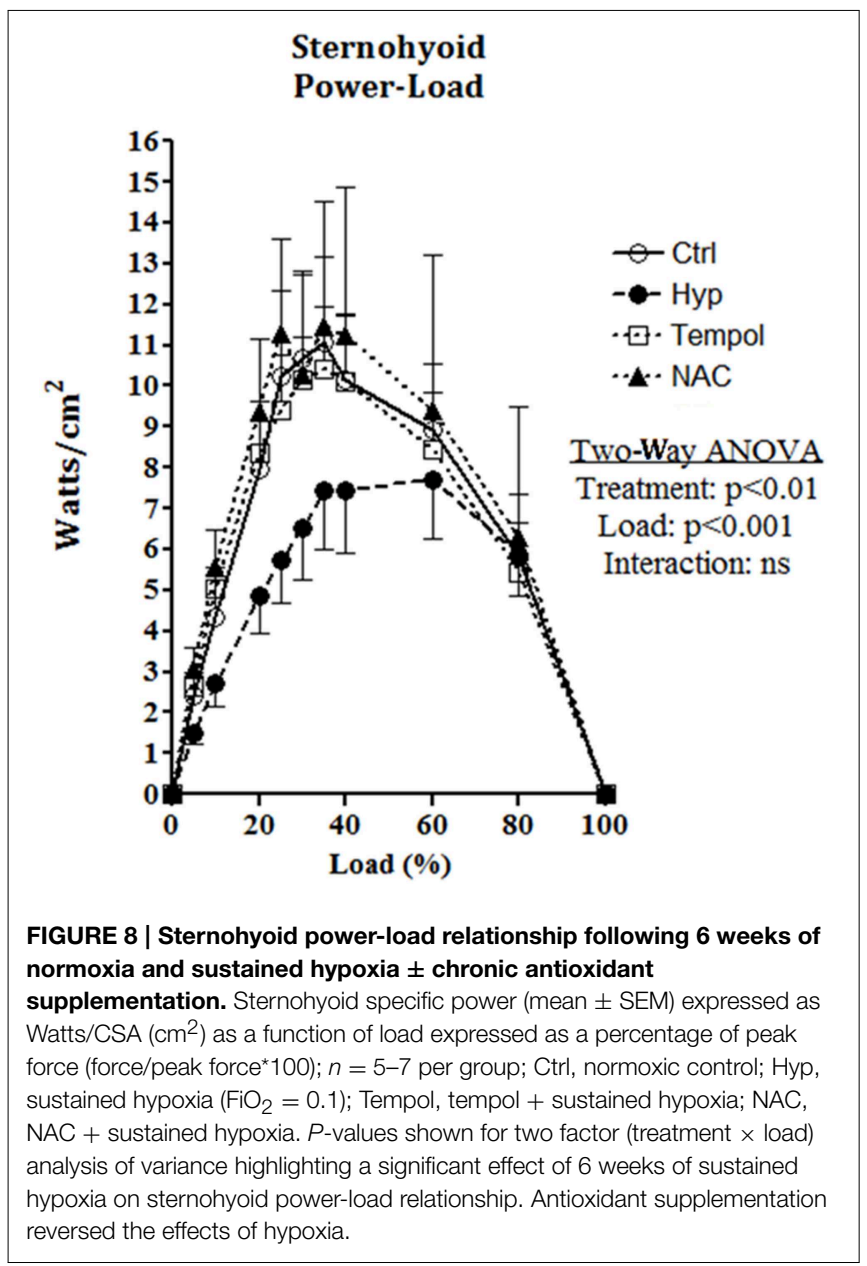

differential structural and functional remodeling reported in previous studies (El-Khoury et al., 2003, 2012; Faucher et al., 2005; Gamboa and Andrade, 2010, 2012; McMorrow et al., 2011; Carberry et al., 2014). This, in turn, may be of clinical significance given that $\mathrm{CH}$ is potentially implicated in the progression of respiratory diseases.

Clearly there is differential muscle protein redox remodeling which appears unrelated to fiber type per se given the similarities between the EDL and sternohyoid muscles, and unrelated to respiratory vs. limb muscle differences per se given the differences observed in the EDL compared with the soleus. As the soleus is a postural muscle, it exhibits greater contractile activity than the EDL which is used for more powerful movements of the limbs. The combination of activity and hypoxic exposure is potentially synergistic in driving protein oxidation, with reflex hyperventilation and hypoxia combining to drive protein oxidation in the sternohyoid. Furthermore, a comparison of basal carbonyl signals from sternohyoid and limb muscle proteomes suggests that basal workload of a given muscle is more important in determining carbonylation of proteins than fiber type per se.

$2 \mathrm{D}$ redox proteomic profiling of the sternohyoid muscle after 6 weeks of $\mathrm{CH}$ exposure reveals key proteins in muscle that are targeted by ROS, many of which are redox modified in COPD muscle (Marin-Corral et al., 2009). It is clear from Table 2 that extensive remodeling occurs to mitochondrial, metabolic, and associated proteins, suggesting that the mitochondria are the primary source of remodeling stress. Reflex hyperventilation increases metabolic demand and subsequent metabolic substrate flux to the respiratory chain. With hypoxia, stockpiling of electrons occurs, increasing electron leak and subsequent ROS formation. This is supported by the findings of decreased muscle mitochondrial density and mitochondrial remodeling in hypoxia, high altitude, and respiratory-related diseases (Hoppeler et al., 1990, 2003; Gosker et al., 2000; Wijnhoven et al., 2006; Viganò et al., 2008; Gamboa and Andrade, 2010, 2012). The fold change in free thiol content following 1 week of $\mathrm{CH}$ is greatest in soleus $>$ EDL $>$ sternohyoid suggesting that fiber type, more so than contractile activity, is key to this change.

EDL free thiol content remains elevated above control whereas carbonyl content was unchanged after 6 weeks of $\mathrm{CH}$; however the pattern of change is similar to the sternohyoid and soleus muscles. It is likely to be a combination of hypoxia, muscle fiber composition, and workload in hypoxia that accounts for the differential changes in respiratory and limb muscle protein oxidation and functional changes. In keeping with the notion of muscle specific effects of $\mathrm{CH}$, other studies have reported differential effects of oxidation, based on carbonyl and thiol measurements as well as other indicators of altered cellular oxidative/reductive state which are proposed to depend on the activity and/or local cellular environment of the relevant protein (Haycock et al., 1998; Kadiiska et al., 2005; El-Shafey et al., 2011). See additional discussion in the supplementary file. 


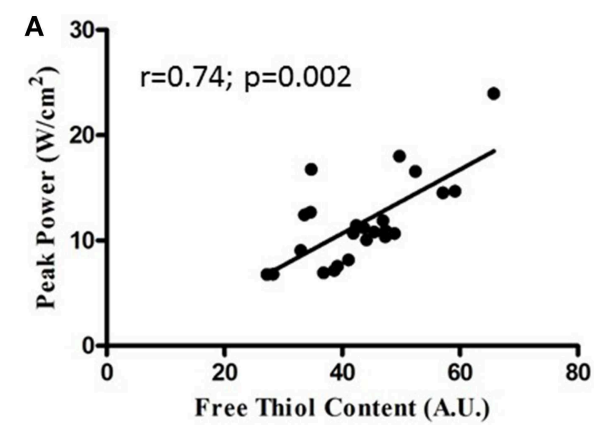

FIGURE 9 | Relationship between sternohyoid power and oxidative stress markers. Relationship between sternohyoid specific peak power and muscle oxidative stress markers [protein free thiol content (A) and carbonyl

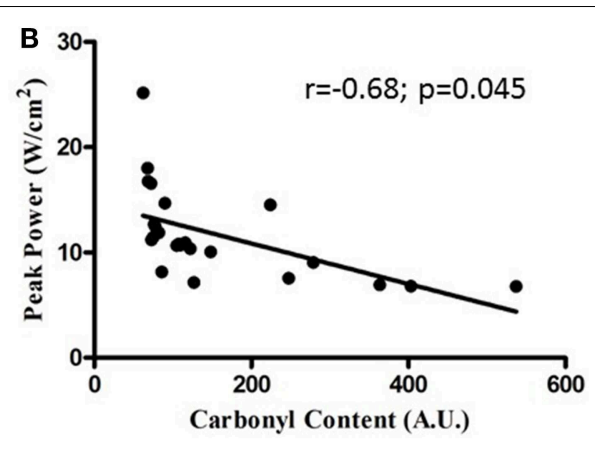

content (B)] plotting data from all animals in the second cohort of studies; $n=24$. Note the correlation coefficients and statistically significant relationships.

\section{Muscle Redox Signaling}

Decreased sternohyoid GAPDH activity with progressive hypoxia is consistent with the decreased expression measured by proteomic profiling after 6 weeks of $\mathrm{CH}$. $\mathrm{CH}$-induced changes in $\mathrm{LDH}$ activity in the sternohyoid follow a similar pattern to GAPDH. As muscle function and metabolism are intrinsically interlinked through HIF signaling (Semenza et al., 1994; Vogt et al., 2001; Kim et al., 2006), one might have expected a $\mathrm{CH}$-induced increase in HIF- $1 \alpha$ content. However, decreased GAPDH expression and decreased GAPDH and LDH activities observed in the sternohyoid muscle of our mouse model are suggestive of decreased HIF- $1 \alpha$ content. Interestingly, after 6 weeks of $\mathrm{CH}$ exposure we observed that there was no change in sternohyoid HIF- $1 \alpha$ content. It is plausible that the degree of hypoxia experienced by the sternohyoid may change temporally with acclimatization to hypoxia such that HIF- $1 \alpha$ may have been activated earlier in the exposure. Of note, for example, GAPDH activity is increased in sternohyoid muscle after 1 but not 3 weeks of $\mathrm{CH}$. Protein carbonylation is elevated in $\mathrm{CH}$ sternohyoid after 6 weeks suggesting that although ROS are presumably elevated in the muscle there is no ROS-dependent HIF- $1 \alpha$ activation. Moreover, antioxidant supplementation did not affect HIF- $1 \alpha$ content in $\mathrm{CH}$ sternohyoid. Thus, our results suggest that redox modulation of sternohyoid metabolism and function is HIF- $1 \alpha$ independent.

The MAPK proteins are involved in a diverse array of cellular signaling events and are vital to muscle growth and homeostasis. p38 activity in muscle is strongly associated with promoting atrophy in COPD limb muscle (Lemire et al., 2012) and is potentially required for hypoxia signaling of HIF via mitochondrial ROS production (Emerling et al., 2005). However, neither HIF-1 $\alpha$ content nor chymotrypsin-like $20 \mathrm{~S}$ proteasome activity changed in the sternohyoid muscle following $\mathrm{CH}$. Indeed, hypertrophy of fast fibers in the sternohyoid is reported following $\mathrm{CH}$ exposure in the rat (McMorrow et al., 2011) suggesting enhanced protein synthesis. This is especially interesting, as the present study has established for the first time, that the $\mathrm{CH}$ sternohyoid has decreased (not increased) power-generating capacity, highlighting a potent redox-dependent inhibitory effect of $\mathrm{CH}$ on the contractile machinery of the airway dilator muscle, rather than $\mathrm{CH}$-induced muscle atrophy.

p-JNK content is decreased in the sternohyoid following $\mathrm{CH}$ exposure. Differential regulation of p38 and JNK occurs at the MAP2K level and is potentially influenced by contractile activity and mechanical stress (Sawada et al., 2001). The combination of hypoxic/redox stress, muscle fiber type combination, and mechanical activity of the sternohyoid is likely important in determining the stress kinase response to $\mathrm{CH}$ exposure. A ROS/pJNK-dependent mechanism is implicated in $\mathrm{CH}$-induced sternohyoid dysfunction but it is important to note that antioxidant supplementation did not prevent the $\mathrm{CH}$-induced decrease in $\mathrm{p}$ JNK (or p-ERK1/2), whereas antioxidants prevented sternohyoid redox stress and contractile dysfunction following $\mathrm{CH}$ exposure.

\section{Sternohyoid Isotonic Performance}

The sternohyoid force- and power-generating capacity was significantly depressed by $\mathrm{CH}$ exposure. Muscle oxidative stress markers and contractile power were significantly correlated; moreover, antioxidant supplementation during $\mathrm{CH}$ exposure prevented both protein redox stress and contractile dysfunction. Therefore, we posit that $\mathrm{CH}$-induced redox remodeling of key proteins in metabolism and the contractile apparatus is central to $\mathrm{CH}$-induced sternohyoid muscle dysfunction. Concerning the potential clinical relevance of our findings, sternohyoid dysfunction could serve to increase obstructive airway events in vivofurther disrupting respiratory homeostasis in diseases characterized by hypoxic stress. We speculate that $\mathrm{CH}$-induced redox remodeling and functional deficit in pharyngeal dilator muscles potentially underpins the higher prevalence of OSA observed in COPD patients (the overlap syndrome) (Owens and Malhotra, 2010).

\section{Summary and Conclusions}

This study highlights the application of a redox proteomics approach to a translational animal model of hypoxia. $\mathrm{CH}$ exposure causes progressive redox remodeling in the sternohyoid (upper airway dilator) muscle with differential responses to limb muscles. $\mathrm{CH}$ results in metabolic protein structural remodeling 
with resultant changes in enzyme activity. Redox and expression changes were shown to occur to various protein chaperones including those important to cross-bridge maintenance. Ultimately, it appears that $\mathrm{CH}$-induced redox changes result in functional deficit in the sternohyoid, given that antioxidant supplementation during $\mathrm{CH}$ exposure prevents both protein stress and functional impairment. We hypothesize a pivotal role for ROS in pharyngeal dilator muscle structural and functional (mal)adaptations to $\mathrm{CH}$. The putative role of hypoxia in driving respiratory muscle remodeling in human respiratory disease warrants investigation.

\section{Author Contributions}

The study was conceived and designed by PL and KO. Experiments and data analyses were performed by PL in the laboratories

\section{References}

Aiken, C. T., Kaake, R. M., Wang, X., and Huang, L. (2011). Oxidative stressmediated regulation of proteasome complexes. Mol. Cell. Proteomics 10, R110.006924. doi: 10.1074/mcp.R110.006924

Bradford, A., McGuire, M., and O'Halloran, K. D. (2005). Does episodic hypoxia affect upper airway dilator muscle function? Implications for the pathophysiology of obstructive sleep apnoea. Respir. Physiol. Neurobiol. 147, 223-234. doi: 10.1016/j.resp.2005.04.001

Carberry, J. C., McMorrow, C., Bradford, A., Jones, J. F. X., and O'Halloran, K. D. (2014). Effects of sustained hypoxia on sternohyoid and diaphragm muscle during development. Eur. Respir. J. 43, 1149-1158. doi: $10.1183 / 09031936.00139512$

Chaudhary, P., Suryakumar, G., Prasad, R., Singh, S. N., Ali, S., and Ilavazhagan, G. (2012). Chronic hypobaric hypoxia mediated skeletal muscle atrophy: role of ubiquitin-proteasome pathway and calpains. Mol. Cell. Biochem. 364, 101-113. doi: $10.1007 / \mathrm{s} 11010-011-1210-\mathrm{x}$

Cole, C., Coelho, A. V., James, R. H., Connelly, D., and Sheehan, D. (2014). Proteomic responses to metal-induced oxidative stress in hydrothermal vent-living mussels, Bathymodiolus sp., on the Southwest Indian Ridge. Mar. Env. Res. 96, 29-37. doi: 10.1016/j.marenvres.2013.09.003

Dalle-Donne, I., Aldini, G., Carini, M., Colombo, R., Rossi, R., and Milzani, A. (2006). Protein carbonylation, cellular dysfunction, and disease progression. J. Cell. Mol. Med. 10, 389-406. doi: 10.1111/j.1582-4934.2006.tb00407.x

Doucet, M., Debigaré, R., Joanisse, D. R., Côté, C., Leblanc, P., Grégoire, J., et al. (2004). Adaptation of the diaphragm and the vastus lateralis in mild-to-moderate COPD. Eur. Respir. J. 24, 971-979. doi: 10.1183/09031936.04.00020204

Doucet, M., Dubé, A., Joanisse, D. R., Debigaré, R., Michaud, A., Paré, M.-È., et al. (2010). Atrophy and hypertrophy signalling of the quadriceps and diaphragm in COPD. Thorax 65, 963-970. doi: 10.1136/thx.2009.133827

Dyballa, N., and Metzger, S. (2009). Fast and sensitive colloidal coomassie G250 staining for proteins in polyacrylamide gels. J. Vis. Exp. 30:e1431. doi: $10.3791 / 1431$

Edge, D., Jones, J. F. X., Bradford, A., and O'Halloran, K. D. (2012). Effect of chronic intermittent hypoxia on reflex recruitment of sternohyoid EMG during airway obstruction in the anaesthetised rat. Proc Physiol Soc 27, PC223.

Edge, D., McDonald, F. B., Jones, J. F. X., Bradford, A., and O'Halloran, K. D. (2014). Effect of chronic intermittent hypoxia on the reflex recruitment of the genioglossus during airway obstruction in the anesthetized rat. Prog. Brain Res. 209, 147-168. doi: 10.1016/B978-0-444-63274-6.00008-4

El-Khoury, R., Bradford, A., and O'Halloran, K. D. (2012). Chronic hypobaric hypoxia increases isolated rat fast-twitch and slow-twitch limb muscle force and fatigue. Physiol. Res. 61, 195-201.

El-Khoury, R., O'Halloran, K. D., and Bradford, A. (2003). Effects of chronic hypobaric hypoxia on contractile properties of rat sternohyoid and diaphragm of $\mathrm{KO}$ and DS. Mass spectrometry experiments were performed and analyzed by RS in the laboratory of AV. The manuscript was written by $\mathrm{PL}$ and $\mathrm{KO}$ with contributions from the other authors.

\section{Acknowledgments}

This project was funded by The Health Research Board (Ireland), and by the Strategic Research Fund, University College Cork, Ireland.

\section{Supplementary Material}

The Supplementary Material for this article can be found online at: http://journal.frontiersin.org/article/10.3389/fphys. 2015.00122/abstract muscles. Clin. Exp. Pharmacol. Physiol. 30, 551-554. doi: 10.1046/j.14401681.2003.03874.x

El-Shafey, A. F., Armstrong, A. E., Terrill, J. R., Grounds, M. D., and Arthur, P. G. (2011). Screening for increased protein thiol oxidation in oxidatively stressed muscle tissue. Free Radic. Res. 45, 991-999. doi: 10.3109/10715762.2011.590136

Emerling, B. M., Platanias, L. C., Black, E., Nebreda, A. R., Davis, R. J., and Chandel, N. S. (2005). Mitochondrial reactive oxygen species activation of p38 mitogenactivated protein kinase is required for hypoxia signaling. Mol. Cell. Biol. 25, 4853-4862. doi: 10.1128/MCB.25.12.4853-4862.2005

Faucher, M., Guillot, C., Marqueste, T., Kipson, N., Mayet-Sornay, M.-H., Desplanches, D., et al. (2005). Matched adaptations of electrophysiological, physiological, and histological properties of skeletal muscles in response to chronic hypoxia. Pflügers Arch. 450, 45-52. doi: 10.1007/s00424-004-1370-6

Gamboa, J. L., and Andrade, F. H. (2010). Mitochondrial content and distribution changes specific to mouse diaphragm after chronic normobaric hypoxia. Am. J. Physiol. Regul. Integr. Comp. Physiol. 298, R575-R583. doi: 10.1152/ajpregu.00320.2009

Gamboa, J. L., and Andrade, F. H. (2012). Muscle endurance and mitochondrial function after chronic normobaric hypoxia: contrast of respiratory and limb muscles. Pflügers Arch. 463, 327-338. doi: 10.1007/s00424-011-1057-8

Gosker, H. R., Wouters, E. F., van der Vusse, G. J., and Scholsa, M. (2000). Skeletal muscle dysfunction in chronic obstructive pulmonary disease and chronic heart failure: underlying mechanisms and therapy perspectives. Am. J. Clin. Nutr. 71, 1033-1047.

Haycock, J. W., Mac Neil, S., and Mantle, D. (1998). Differential protein oxidation in Duchenne and Becker muscular dystrophy. Neuroreport 9, 2201-2207. doi: 10.1097/00001756-199807130-00010

Hoppeler, H., Howald, H., and Cerretelli, P. (1990). Human muscle structure after exposure to extreme altitude. Experientia 46, 1185-1187. doi 10.1007/BF01936933

Hoppeler, H., Vogt, M., Weibel, E. R., and Flück, M. (2003). Response of skeletal muscle mitochondria to hypoxia. Exp. Physiol. 88, 109-119. doi: 10.1113/eph8802513

Howald, H., Pette, D., Simoneau, J. A., Uber, A., Hoppeler, H., and Cerretelli, P. (1990). Effect of chronic hypoxia on muscle enzyme activities. Int. J. Sport. Med. 11(Suppl. 1), S10-S14. doi: 10.1055/s-2007-1024847

Hu, W., Culloty, S., Darmody, G., Lynch, S., Davenport, J., Ramirez-Garcia, S., et al. (2014). Toxicity of copper oxide nanoparticles in the blue mussel, Mytilus edulis: a redox proteomic investigation. Chemosphere 108, 289-299. doi: 10.1016/j.chemosphere.2014.01.054

Kadiiska, M. B., Gladen, B. C., Baird, D. D., Germolec, D., Graham, L. B., Parker, C. E., et al. (2005). Biomarkers of oxidative stress study II: are oxidation products of lipids, proteins, and DNA markers of CCl4 poisoning? Free Radic. Biol. Med. 38, 698-710. doi: 10.1016/j.freeradbiomed.2004.09.017

Kim, J., Tchernyshyov, I., Semenza, G. L., and Dang, C. V. (2006). HIF-1mediated expression of pyruvate dehydrogenase kinase: a metabolic switch 
required for cellular adaptation to hypoxia. Cell Metab. 3, 177-185. doi: 10.1016/j.cmet.2006.02.002

Lemire, B. B., Debigaré, R., Dubé, A., Thériault, M.-E., Côté, C. H., and Maltais, F. (2012). MAPK signaling in the quadriceps of patients with chronic obstructive pulmonary disease. J. Appl. Physiol. 113, 159-166. doi: 10.1152/japplphysiol.01518.2011

Levine, S., Bashir, M. H., Clanton, T. L., Powers, S. K., and Singhal, S. (2013). COPD elicits remodeling of the diaphragm and vastus lateralis muscles in humans. J. Appl. Physiol. 114, 1235-1245. doi: 10.1152/japplphysiol.01121.2012

Marin-Corral, J., Minguella, J., Ramírez-Sarmiento, A. L., Hussain, S. N. A., Gea, J., and Barreiro, E. (2009). Oxidised proteins and superoxide anion production in the diaphragm of severe COPD patients. Eur. Respir. J. 33, 1309-1319. doi: $10.1183 / 09031936.00072008$

McClung, J. M., Whidden, M. A., Kavazis, A. N., Falk, D. J., Deruisseau, K. C., and Powers, S. K. (2008). Redox regulation of diaphragm proteolysis during mechanical ventilation. Am. J. Physiol. Regul. Integr. Comp. Physiol. 294, R1608-R1617. doi: 10.1152/ajpregu.00044.2008

McDonald, F. B., Edge, D., and O'Halloran, K. D. (2014). Chronic nitric oxide synthase inhibition does not impair upper airway muscle adaptation to chronic intermittent hypoxia in the rat. Prog. Brain Res. 212, 237-251. doi: 10.1016/B978-0-444-63488-7.00012-4

McDonald, F. B., Skelly, J. R., and O'Halloran, K. D. (2015). The $\beta_{2}$-adrenoceptor agonist terbutaline recovers rat pharyngeal dilator muscle force decline during severe hypoxia. Oral Dis. 21, e121-e127. doi: 10.1111/odi.12247

McMorrow, C., Fredsted, A., Carberry, J., O’Connell, R. A., Bradford, A., Jones, J. F. X., et al. (2011). Chronic hypoxia increases rat diaphragm muscle endurance and sodium-potassium ATPase pump content. Eur. Respir. J. 37, 1474-1481. doi: 10.1183/09031936.00079810

McNicholas, W. T. (2009). Chronic obstructive pulmonary disease and obstructive sleep apnea: overlaps in pathophysiology, systemic inflammation, and cardiovascular disease. Am. J. Respir. Crit. Care Med. 180, 692-700. doi: 10.1164/rccm.200903-0347PP

Murray, A. J. (2009). Metabolic adaptation of skeletal muscle to high altitude hypoxia: how new technologies could resolve the controversies. Genome Med. 1:117. doi: $10.1186 / \mathrm{gm} 117$

O'Halloran, K. D., McGuire, M., O’Hare, T., and Bradford, A. (2002). Chronic intermittent asphyxia impairs rat upper airway muscle responses to acute hypoxia and asphyxia. Chest 122, 269-275. doi: 10.1378/chest.122.1.269

O'Connell, R. A., Carberry, J., and O'Halloran, K. D. (2013). Sternohyoid and diaphragm muscle form and function during postnatal development in the rat. Exp. Physiol. 98, 1386-1400. doi: 10.1113/expphysiol.2013.073346

O'Halloran, K. D. (2006). Effects of nicotine on rat sternohyoid muscle contractile properties. Respir. Physiol. Neurobiol. 150, 200-210. doi: 10.1016/j.resp.2005.05.018

Orozco-Levi, M. (2003). Structure and function of the respiratory muscles in patients with COPD: impairment or adaptation? Eur. Respir. J. Suppl. 46, 41s-51s. doi: 10.1183/09031936.03.00004607

Owens, R. L., Eckert, D. J., Yeh, S. Y., and Malhotra, A. (2008). Upper airway function in the pathogenesis of obstructive sleep apnea: a review of the current literature. Curr. Opin. Pulm. Med. 14, 519-524. doi: 10.1097/MCP.0b013e3283130f66

Owens, R. L., and Malhotra, A. (2010). Sleep-disordered breathing and COPD: the overlap syndrome. Respir Care 55, 1333-1344; discussion: 1344-1346.

Petrof, B. J., Pack, A. I., Kelly, A. M., Eby, J., and Hendricks, J. C. (1994). Pharyngeal myopathy of loaded upper airway in dogs with sleep apnea. J. Appl. Physiol. $76,1746-1752$

Puig-Vilanova, E., Rodriguez, D. A., Lloreta, J., Ausin, P., Pascual-Guardia, S., Broquetas, J., et al. (2015). Oxidative stress, redox signaling pathways, and autophagy in cachectic muscles of male patients with advanced COPD and lung cancer. Free Radic. Biol. Med. 79, 91-108. doi: 10.1016/j.freeradbiomed.2014.11.006

Rainville, L.-C., Carolan, D., Varela, A. C., Doyle, H., and Sheehan, D. (2014). Proteomic evaluation of citrate-coated silver nanoparticles toxicity in Daphnia magna. Analyst 139, 1678-1686. doi: 10.1039/c3an02160b
Sawada, Y., Nakamura, K., Doi, K., Takeda, K., Tobiume, K., Saitoh, M., et al. (2001). Rap1 is involved in cell stretching modulation of p38 but not ERK or JNK MAP kinase. J. Cell Sci. 114, 1221-1227.

Semenza, G. L., Roth, P. H., Fang, H. M., and Wang, G. L. (1994). Transcriptional regulation of genes encoding glycolytic enzymes by hypoxia-inducible factor 1 . J. Biol. Chem. 269, 23757-23763.

Shortt, C. M., and O'Halloran, K. D. (2014). Hydrogen peroxide alters sternohyoid muscle function. Oral Dis. 20, 162-170. doi: 10.1111/odi.12084

Skelly, J. R., Bradford, A., Jones, J. F., and O'Halloran, K. D. (2010). Superoxide scavengers improve rat pharyngeal dilator muscle performance. Am. J. Respir. Cell Mol. Biol. 42, 725-731. doi: 10.1165/rcmb.2009-0160OC

Skelly, J. R., Edge, D., Shortt, C. M., Jones, J. F., Bradford, A., and O'Halloran, K. D. (2012a). Respiratory control and sternohyoid muscle structure and function in aged male rats: decreased susceptibility to chronic intermittent hypoxia. Respir. Physiol. Neurobiol. 180, 175-182. doi: 10.1016/j.resp.2011.11.004

Skelly, J. R., Edge, D., Shortt, C. M., Jones, J. F., Bradford, A., and O'Halloran, K. D. (2012b). Tempol ameliorates pharyngeal dilator muscle dysfunction in a rodent model of chronic intermittent hypoxia. Am. J. Respir. Cell Mol. Biol. 46, 139-148. doi: 10.1165/rcmb.2011-0084OC

Skelly, J. R., O'Connell, R. A., Jones, J. F., and O'Halloran, K. D. (2011). Structural and functional properties of an upper airway dilator muscle in aged obese male rats. Respiration 82, 539-549. doi: 10.1159/000332348

Skelly, J. R., Rowan, S. C., Jones, J. F., and O'Halloran, K. D. (2013). Upper airway dilator muscle weakness following intermittent and sustained hypoxia in the rat: effects of a superoxide scavenger. Physiol. Res. 16, 187-196.

Van Lunteren, E., Haxhiu, M. A., and Cherniack, N. S. (1987). Relation between upper airway volume and hyoid muscle length. J. Appl. Physiol. 63, 1443-1449.

Van Lunteren, E., and Pollarine, J. (2010). Improvement of diaphragm and limb muscle isotonic contractile performance by $\mathrm{K}+$ channel blockade. J. Neuroeng. Rehabil. 7:1. doi: 10.1186/1743-0003-7-1

Van Lunteren, E., Pollarine, J., and Moyer, M. (2007). Isotonic contractile impairment due to genetic CLC-1 chloride channel deficiency in myotonic mouse diaphragm muscle. Exp. Physiol. 92, 717-729. doi: 10.1113/expphysiol.2007.038190

Viganò, A., Ripamonti, M., De Palma, S., Capitanio, D., Vasso, M., Wait, R., et al. (2008). Proteins modulation in human skeletal muscle in the early phase of adaptation to hypobaric hypoxia. Proteomics 8, 4668-4679. doi: 10.1002/pmic.200800232

Vogt, M., Puntschart, A., Geiser, J., Zuleger, C., Billeter, R., and Hoppeler, H. (2001). Molecular adaptations in human skeletal muscle to endurance training under simulated hypoxic conditions. J. Appl. Physiol. 91, 173-182.

Watchko, J. F., Daood, M. J., Sieck, G. C., LaBella, J. J., Ameredes, B. T., Koretsky, A. P. et al. (1997). Combined myofibrillar and mitochondrial creatine kinase deficiency impairs mouse diaphragm isotonic function. J. Appl. Physiol. 82, 1416-1423.

Wheaton, W. W., and Chandel, N. S. (2011). Hypoxia. 2. Hypoxia regulates cellular metabolism. Am. J. Physiol. Cell Physiol. 300, C385-C393. doi: 10.1152/ajpcell.00485.2010

Wijnhoven, J. H., Janssen, J. M., van Kuppevelt, T. H., Rodenburg, R. J. T., and Dekhuijzen, P. N. R. (2006). Metabolic capacity of the diaphragm in patients with COPD. Respir. Med. 100. 1064-1071. doi: 10.1016/j.rmed.2005.09.029

Zuo, L., and Clanton, T. L. (2005). Reactive oxygen species formation in the transition to hypoxia in skeletal muscle. Am. J. Physiol. Cell Physiol. 289, C207-C216. doi: 10.1152/ajpcell.00449.2004

Conflict of Interest Statement: The authors declare that the research was conducted in the absence of any commercial or financial relationships that could be construed as a potential conflict of interest.

Copyright () 2015 Lewis, Sheehan, Soares, Varela Coelho and O'Halloran. This is an open-access article distributed under the terms of the Creative Commons Attribution License (CC BY). The use, distribution or reproduction in other forums is permitted, provided the original author(s) or licensor are credited and that the original publication in this journal is cited, in accordance with accepted academic practice. No use, distribution or reproduction is permitted which does not comply with these terms. 